\title{
Open
}

\section{Targeted deletion of MyD88 in intestinal epithelial cells results in compromised antibacterial immunity associated with downregulation of polymeric immunoglobulin receptor, mucin-2, and antibacterial peptides}

\begin{abstract}
AL Frantz ${ }^{1}$, EW Rogier ${ }^{1}$, CR Weber ${ }^{2}$, L Shen $^{2}$, DA Cohen ${ }^{1}$, LA Fenton ${ }^{1}$, MEC Bruno $^{1}$ and CS Kaetzel $^{1}$
Intestinal epithelial cells (IECs) form a physical and immunological barrier that separates the vast gut microbiota from host tissues. MyD88-dependent Toll-like receptor signaling is a key mediator of microbial-host cross-talk. We examined the role of epithelial MyD88 expression by generating mice with an IEC-targeted deletion of the Myd88 gene (MyD88 ${ }^{\triangle \mathrm{IEC}}$ ). Loss of epithelial MyD88 signaling resulted in increased numbers of mucus-associated bacteria; translocation of bacteria, including the opportunistic pathogen Klebsiella pneumoniae, to mesenteric lymph nodes; reduced transmucosal electrical resistance; impaired mucus-associated antimicrobial activity; and downregulated expression of polymeric immunoglobulin receptor (the epithelial IgA transporter), mucin-2 (the major protein of intestinal mucus), and the antimicrobial peptides Reglll $\gamma$ and Defa-rs1. We further observed significant differences in the composition of the gut microbiota between MyD88 ${ }^{\triangle \mathrm{IEC}}$ mice and wild-type littermates. These physical, immunological, and microbial defects resulted in increased susceptibility of $M y D 88^{\Delta \mathrm{IEC}}$ mice to experimental colitis. We conclude that MyD88 signaling in IECs is crucial for maintenance of gut homeostasis.
\end{abstract}

The mammalian intestine harbors an estimated 100 trillion microorganisms, which normally maintain a mutually beneficial relationship with the host. ${ }^{1}$ The intestinal epithelium provides a physical barrier as well as innate immune defense, preventing this vast community of microbes from entering host tissues. ${ }^{2}$ Defects in epithelial barrier and immune functions can lead to infections with opportunistic and pathogenic microbes ${ }^{3}$ and contribute to the etiology of inflammatory bowel disease (IBD). ${ }^{4}$ Cross-talk between the gut microbiota and intestinal epithelial cells (IECs) is mediated by pattern recognition receptors, including the Toll-like receptor (TLR) family, ${ }^{5}$ leading to expression of gene products that enhance epithelial barrier function and innate immunity. TLR signaling in the gut is a double-edged sword; while physiological TLR signaling promotes intestinal homeostasis in healthy individuals, excessive TLR signaling in response to invasive microbes can exacerbate intestinal inflammation. ${ }^{6}$ The cytoplasmic adaptor protein MyD88 transduces signals from TLRs that recognize bacterial products. ${ }^{7}$ The finding that Myd88-deficient mice exhibited increased susceptibility to chemically induced colitis highlighted the importance of physiological TLR signaling for protection of the epithelial barrier. $^{8}$ Studies using bone marrow chimeras of Myd88-deficient and wild-type mice in several mouse models of colitis demonstrated that MyD88 signaling in hematopoietic cells was required for the development of intestinal inflammation, whereas MyD88 signaling in non-hematopoietic cells was required for host survival. ${ }^{9,10}$ Here we used cell type-specific deletion of the Myd88 gene to investigate the role of epithelial-specific MyD88 signaling in antibacterial immunity and protection against intestinal inflammation.

Secretory immunoglobulin A (SIgA) acts as the first line of antigen-specific immunity at the interface between the gut microbiota and the intestinal epithelium. ${ }^{11}$ Polymeric IgA secreted by plasma cells in the intestinal lamina propria is

1Department of Microbiology, Immunology \& Molecular Genetics, University of Kentucky College of Medicine, Lexington, Kentucky, USA. ${ }^{2}$ Department of Pathology, The University of Chicago, Chicago, Illinois, USA. Correspondence: CS Kaetzel (cskaet@uky.edu) 
transported across IECs by the polymeric immunoglobulin receptor (pIgR). ${ }^{12}$ Importantly, we found that reduced expression of pIgR was correlated with greater disease severity in patients with $\mathrm{IBD}^{13}$ and in mouse models of experimental colitis. ${ }^{14}$ Our finding that expression of pIgR is regulated in IECs by TLR signaling ${ }^{15}$ suggests that microbial-epithelial cross-talk is crucial for optimal production of SIgA. Consistent with this concept, we found that MyD88-deficient mice had reduced colonic expression of pIgR and deficient transport of SIgA. ${ }^{2}$ However, in that study, it was not determined whether PIgR was regulated directly by MyD 88 signaling in IECs or indirectly by immune cells in the intestinal lamina propria. In the present study, we used targeted deletion of the Myd88 gene to demonstrate an essential role for epithelial-specific MyD88 signaling in maintaining optimal expression of pIgR and transport of SIgA.

The thick layer of intestinal mucus acts to separate luminal bacteria from the epithelial surface. ${ }^{16}$ This mucus is rich in antimicrobial peptides ${ }^{17}$ and associates with SIgA via glycanmediated interactions, ${ }^{18}$ thus forming an immunological as well as a physical barrier against microbial invasion. Here we report that targeted deletion of MyD88 in IECs causes downregulated expression of PIgR, mucin-2 (the major protein constituent of intestinal mucus), and antimicrobial peptides in IECs. We propose a model in which MyD88-dependent bacterialepithelial cross-talk is crucial for the maintenance of physical and immunological barrier functions in the intestine.

\section{RESULTS \\ Loss of MyD88 signaling in colonic epithelial cells (ECs) disturbs the segregation of microbiota and host}

To investigate the role of epithelial MyD88 signaling in intestinal homeostasis, we generated mice with a targeted deletion of the Myd88 gene in IECs (MyD88 ${ }^{\Delta \mathrm{IEC}}$ ) by crossing mice carrying loxP-flanked $M y d 88$ alleles $\left(\mathrm{MyD} 88^{\text {Flox }}\right.$ ) with mice that express Cre recombinase under the control of the IEC-specific Vill promoter. ${ }^{19}$ Levels of MyD88 mRNA were significantly reduced in isolated colonic ECs from MyD88 ${ }^{\triangle \mathrm{IEC}}$ mice at 9 weeks of age (Figure 1a). Immunostaining revealed expression of MyD88 in colonic ECs and lamina propria mononuclear cells of MyD88 ${ }^{\mathrm{Flox}}$ mice, whereas MyD88 ${ }^{\Delta \mathrm{IEC}}$ mice lacked MyD88 expression in ECs but retained expression in lamina propria mononuclear cells (Figure 1b). Compared with MyD88 $8^{\text {Flox }}$ littermates, MyD88 ${ }^{\Delta \mathrm{IEC}}$ mice showed no histological signs of intestinal inflammation at 9 weeks of age (Figure 1b), or when followed up to 12 months (see Supplementary Figure S1 online). No pathological changes in colon morphology were observed. Although there were no differences in numbers of culturable bacteria in feces from MyD8 $88^{\text {Flox }}$ and MyD8 $88^{\Delta \mathrm{IEC}}$ mice, we observed increased mucus-associated colony-forming units (CFU) in MyD88 ${ }^{\triangle \mathrm{IEC}}$ mice (Figure 1c). These differences were not restricted to culturable bacteria, as similar trends were observed when using quantitative reverse transcriptase--PCR of $16 \mathrm{~S}$ rDNA to quantify bacterial numbers (see Supplementary Figure S2 online). Furthermore, increased bacterial attachment to the epithelial surface in MyD88 ${ }^{\triangle \mathrm{IEC}}$ mice was correlated with increased translocation of bacteria to the draining mesenteric lymph nodes (MLNs; Figure 1d, e). Interestingly, about $25 \%$ of bacterial colonies cultured from MLNs of MyD8 $8^{\triangle \mathrm{IEC}}$ mice had a large, mucoid morphology and were identified as Klebsiella pneumoniae by sequencing of $16 \mathrm{~S}$ rRNA genes and biochemical tests (see Supplementary Figure S3 online). No bacteria could be cultured from the spleens of $\mathrm{MyD} 88^{\triangle \mathrm{IEC}}$ mice, suggesting that infection with gut-derived bacteria was confined to the mucosal immune system. These findings indicate that epithelial-specific MyD88 signaling is required for normal segregation of gut commensals from host tissues.

\section{Loss of MyD88 signaling in colonic ECs compromises epithelial barrier function}

We hypothesized that increased epithelial permeability in MyD88 ${ }^{\Delta \mathrm{IEC}}$ mice, coupled with increased numbers of mucusadherent bacteria, could result in leakage of bacteria into the lamina propria and travel via the lymphatics to MLNs. Measurement of transmucosal electrical resistance in isolated colonic tissues revealed significant decreases in MyD88 ${ }^{\Delta \mathrm{IEC}}$ mice, indicative of decreased epithelial barrier function (Figure 2a). This ex vivo analysis was supported by the in vivo observation of elevated levels of serum albumin in the feces of MyD88 ${ }^{\triangle \mathrm{IEC}}$ mice, reflecting leakage of serum proteins into the intestinal lumen (see Supplementary Figure S4 online). To determine whether increased mucosal adherence and epithelial translocation of bacteria in $\mathrm{MyD} 88^{\triangle \mathrm{IEC}}$ mice was selective for opportunistic pathogens such as K. pneumoniae, we treated mice orally for 7 days with an environmental, nonpathogenic strain of Escherichia coli (Nissle 1917) ${ }^{20}$ which had been transformed to kanamycin resistance. We observed similar numbers of $\mathrm{Kan}^{\mathrm{R}}$ E. coli in feces and luminal washes from MyD88 ${ }^{\text {Flox }}$ and MyD88 ${ }^{\triangle \mathrm{IEC}}$ mice, but significantly increased numbers in the colonic mucus of MyD88 ${ }^{\Delta \mathrm{IEC}}$ mice (Figure 2b), consistent with the finding that mucus extracted from MyD $88^{\Delta \mathrm{IEC}}$ mice had reduced antibacterial activity compared with $\mathrm{MyD} 88^{\mathrm{Flox}}$ mice (Figure 2c). However, these $\mathrm{Kan}^{\mathrm{R}}$ E. coli did not translocate to the MLNs of MyD88 ${ }^{\triangle \mathrm{IEC}}$ mice (data not shown). These results suggested that the increased mucosal adherence of bacteria in MyD $88^{\triangle \mathrm{IEC}}$ mice may be non-selective, whereas translocation to the draining lymph nodes may be selective for more aggressive bacteria such as K. pneumoniae.

We hypothesized that loss of epithelial MyD88 signaling could result in increased bacterial invasion of IECs. To assess epithelial invasion independently of the confounding effects of local immune cells, we performed in vitro bacterial invasion assays in the human HT-29 colon carcinoma cell-line. We tested the effects of small hairpin RNA (shRNA)-mediated knockdown of MyD88 (see Supplementary Figure S5a online for documentation of MyD88 depletion) on attachment and invasion of three species of Gram-negative bacteria of the family Enterobacteriaceae: the non-invasive E. coli strain Nissle 1917, the opportunistic pathogen K. pneumoniae (a strain isolated from the MLN of a MyD88 ${ }^{\triangle \mathrm{IEC}}$ mouse), and the invasive pathogen Salmonella typhimurium (strain SL1344) (Figure 2d). Knockdown of MyD88 expression in HT-29 cells resulted in significantly increased adherence of all three bacterial species to 
a

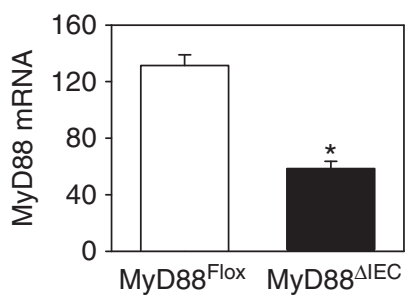

C
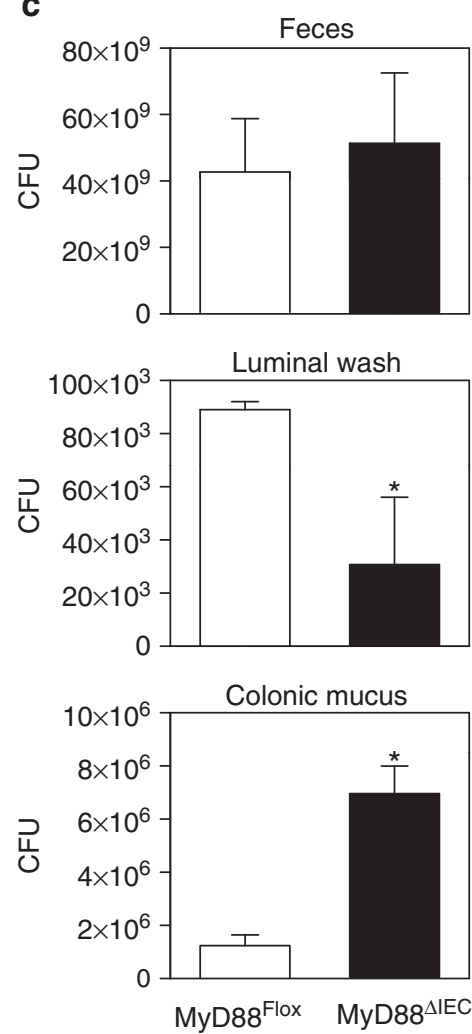

b MyD88Flox
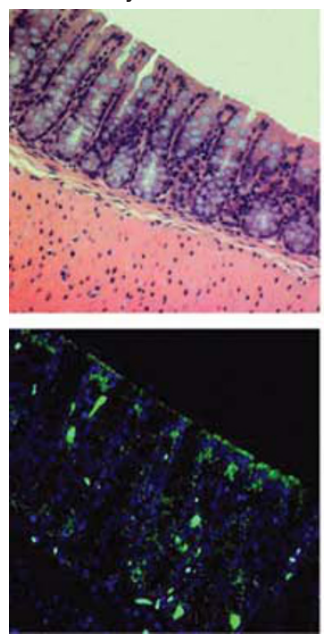

d
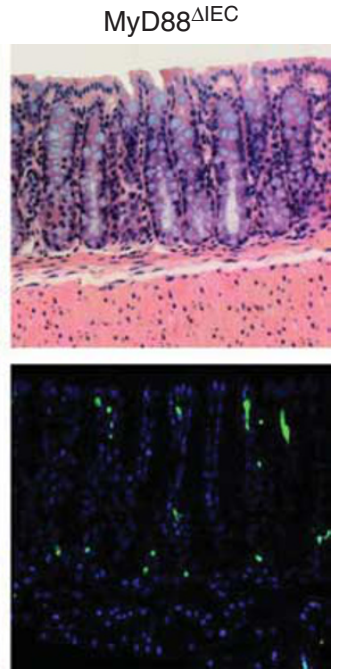

MyD88 $\triangle \mathrm{IEC}$

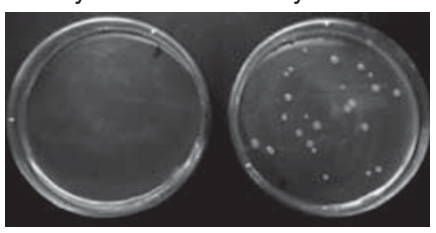

e

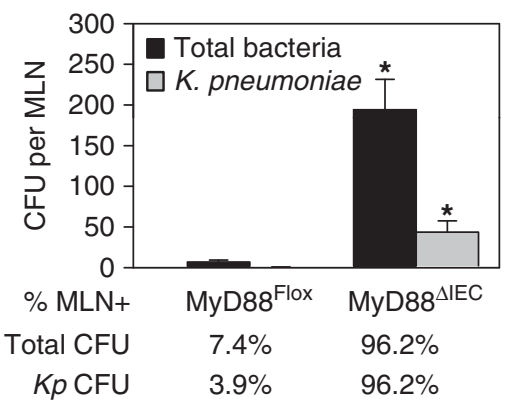

Figure 1 Targeted deletion of MyD88 in intestinal epithelial cells (IECs) results in increased numbers of mucus-associated bacteria and bacterial translocation to mesenteric lymph nodes (MLNs). (a) Mice with a targeted deletion of the Myd88 gene in IECs (MyD88 ${ }^{\Delta \mathrm{IEC}}$ ) were created by crossing mice in which both copies of the MyD88 gene were flanked with loxP sites (MyD88 ${ }^{\mathrm{Flox}}$ ) with mice expressing Cre recombinase under the control of the IEC-specific Vil1 promoter. Levels of MyD88 mRNA were analyzed in colonic epithelial cells isolated from 9-week-old littermate MyD88Flox and MyD88 ${ }^{\triangle \mathrm{IEC}}$ mice by Nanostring nCounter hybridization. mRNA transcript abundance was normalized as described in the Methods section, and expressed as mean \pm s.e.m. $(n=15)$. (b) Colon tissue sections from MyD88 Flox and MyD88 ${ }^{\triangle \mathrm{IEC}}$ mice were stained with hematoxylin and eosin (upper panels) or fluorescein isothiocyanate-labeled antibodies to MyD88 (green) and the nuclear stain 4,6-diamidino-2-phenylindole (blue; lower panels).

(c) Bacterial colony-forming units (CFU) were enumerated following anaerobic culture of fecal homogenates (CFU per g feces), luminal washes (CFU per $\mathrm{ml}$ phosphate-buffered saline), and surface mucus (CFU per $100 \mu \mathrm{l}$ mucus) from colons of MyD88 $8^{\mathrm{Flox}}$ and MyD88 $8^{\Delta \mathrm{EEC}}$ mice. Data are expressed as mean \pm S.e.m. $(n=6)$. (d) Bacterial colonies cultured under anaerobic conditions from MLNs of representative MyD88 $8^{\mathrm{Flox}}$ and MyD88 $8^{\Delta \mathrm{EC}}$ mice. Large mucoid colonies from MyD88 ${ }^{\triangle \mathrm{IEC}}$ mice were identified as Klebsiella pneumoniae $(K p)$ by sequence analysis of $16 \mathrm{~S}$ rRNA genes and biochemical tests (see Supplementary Figure S3 online). (e) CFU of total anaerobic bacteria and K. pneumoniae cultured from MLNs of MyD88 Flox and MyD88 ${ }^{\Delta \mathrm{IEC}}$ mice. Data in the bar graph are expressed as CFU per MLN (mean \pm s.e.m., $n=27$ ). The numbers below the bar graph indicate the percentage of mice of each genotype from which bacteria (total and K. pneumoniae) could be cultured from MLNs. In all panels, asterisks indicate that the mean for MyD88 ${ }^{\Delta \mathrm{IEC}}$ mice is significantly different from the mean for MyD88 ${ }^{\mathrm{Flox}}$ mice $(P<0.05)$.

the epithelial surface. As expected, the magnitude of epithelial invasion by E. coli and K. pneumoniae was dramatically lower than was observed for S. typhimurium, but invasion of all three species was significantly increased when expression of MyD88 was reduced. Taken together, our findings suggest that MyD88 signaling in ECs plays a crucial role in intestinal immunity by increasing the antibacterial activity of epithelial mucus, reducing bacterial adherence to the epithelial surface, maintaining epithelial barrier function, and preventing bacterial invasion of ECs.

\section{Loss of MyD88 signaling in IECs alters the composition of the gut microbiota}

We hypothesized that compromised innate immunity resulting from loss of epithelial MyD88 signaling would affect the balance 
a

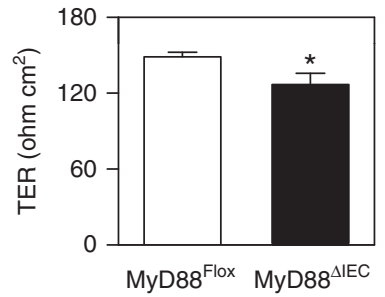

b

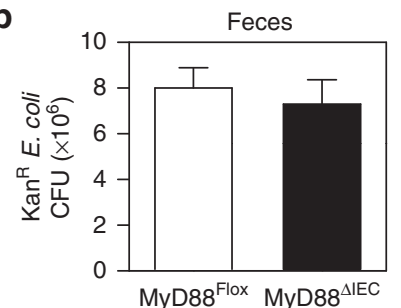

d
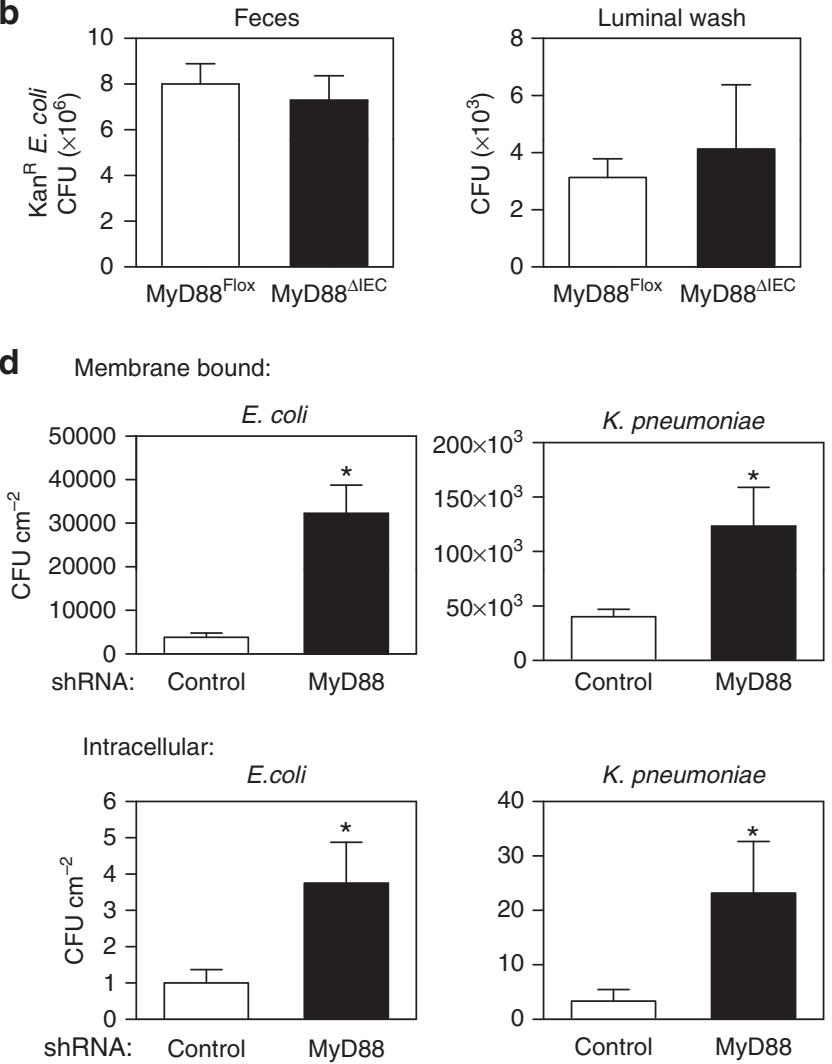

C

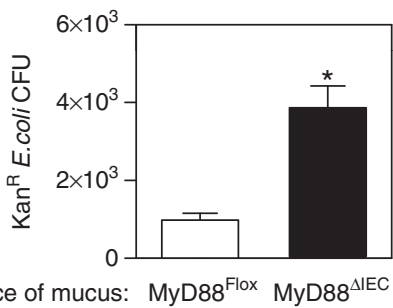

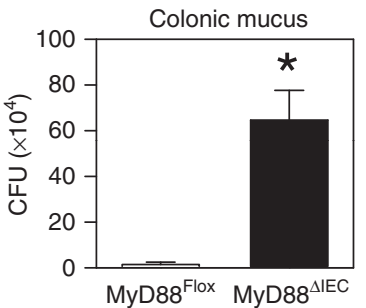
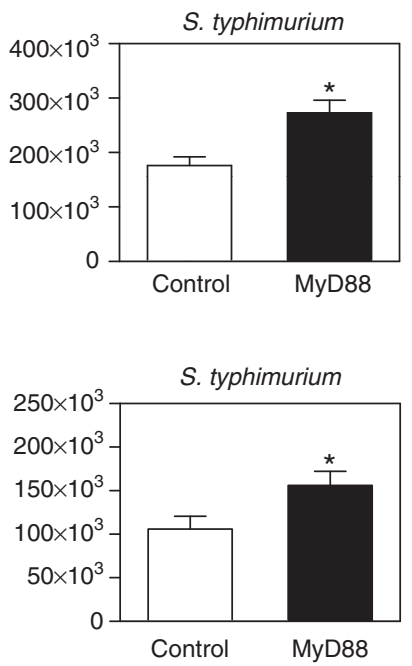

Figure 2 Loss of MyD88 expression in intestinal epithelial cells (IECs) compromises epithelial barrier integrity. (a) Epithelial barrier function. Transmucosal electrical resistance (TER) was analyzed ex vivo in isolated mouse colon tissues placed in Ussing chambers. Data are expressed as means \pm s.e.m. $(n=8)$. (b) Association of exogenous, noninvasive bacteria with colonic mucus. MyD88 ${ }^{\mathrm{Flox}}$ and MyD88 $8^{\Delta \mathrm{ECC}}$ mice were administered Escherichia coli strain Nissle 1917 that had been transformed to kanamycin resistance (Kan ${ }^{R}$ E. coll) at a dose of $2.5 \times 10^{7} \mathrm{CFU} \mathrm{ml}^{-1}$ in the drinking water for 7 days. Kanamycin-resistant colonies were enumerated after anaerobic culture of fecal homogenates (colony-forming units (CFU) per $g$ feces), luminal washes (CFU per ml phosphate-buffered saline), and epithelial-associated mucus (CFU per $100 \mu \mathrm{l}$ mucus). Data are expressed as mean \pm s.e.m. $(n=6)$. (c) Antibacterial activity of colonic mucus. Aliquots of mucus harvested from the colons of MyD88 Flox and MyD88 ${ }^{\Delta \mathrm{IEC}}$ mice were incubated for $15 \mathrm{~min}$ with $10^{6} \mathrm{CFU}$ of $\mathrm{Kan}^{\mathrm{R}} \mathrm{E}$. coli, and then cultured in the presence of kanamycin to enumerate surviving E. coli. Data are expressed as mean \pm s.e.m. $(n=6)$. (d) In vitro bacterial invasion assays. Clones of the HT-29 human colon carcinoma cell line were stably transfected with small hairpin RNA (shRNA) specific for MyD88 or a random control sequence. Cell monolayers $\left(2 \mathrm{~cm}^{2}\right)$ were incubated with $10^{6} \mathrm{CFU}(\mathrm{MOI}$ of $10: 1)$ of E. coli strain Nissle 1917, a strain of Klebsiella pneumoniae isolated from mesenteric lymph nodes of MyD88 ${ }^{\Delta \mathrm{IEC}}$ mice, or Salmonella typhimurium strain SL1344. Membrane-bound CFU were enumerated by anaerobic culture of cell homogenates after washing to remove unbound bacteria, and intracellular CFU were enumerated in parallel plates after $2 \mathrm{~h}$ of treatment of cell monolayers with gentamicin to kill all extracellular bacteria. Data are expressed as mean \pm s.e.m. $(n=6)$. Asterisks indicate that the mean for MyD88 ${ }^{\Delta \mathrm{IEC}}$ mice is significantly different from the mean for MyD88Flox mice (panels a-c) or that the mean for cells expressing MyD88 shRNA is significantly different from the mean for cells expressing control shRNA (d) $(P<0.05)$.

of the gut bacterial community, resulting in an altered composition of the gut microbiota in MyD88 $8^{\mathrm{IIEC}}$ mice. The richness and diversity of fecal bacteria was analyzed by the PhyloChip assay (Second Genome, Inc., San Bruno, CA), a microarraybased method that measures the relative abundance of more than 59,000 individual microbial taxa in fecal DNA by analysis of the entire $16 \mathrm{~S}$ ribosomal RNA gene sequence, ${ }^{21}$ in MyD88 8 Flox and $\mathrm{MyD} 88^{\mathrm{AIEC}}$ mice. Although the overall richness of the fecal microbiota of MyD88 $8^{\text {Flox }}$ and MyD88 ${ }^{\triangle \mathrm{IEC}}$ mice was similar (see Supplementary Figures S6 and S7 online), significant differences were observed in the relative abundance of operational taxonomic units (OTUs, defined as a group of highly similar 

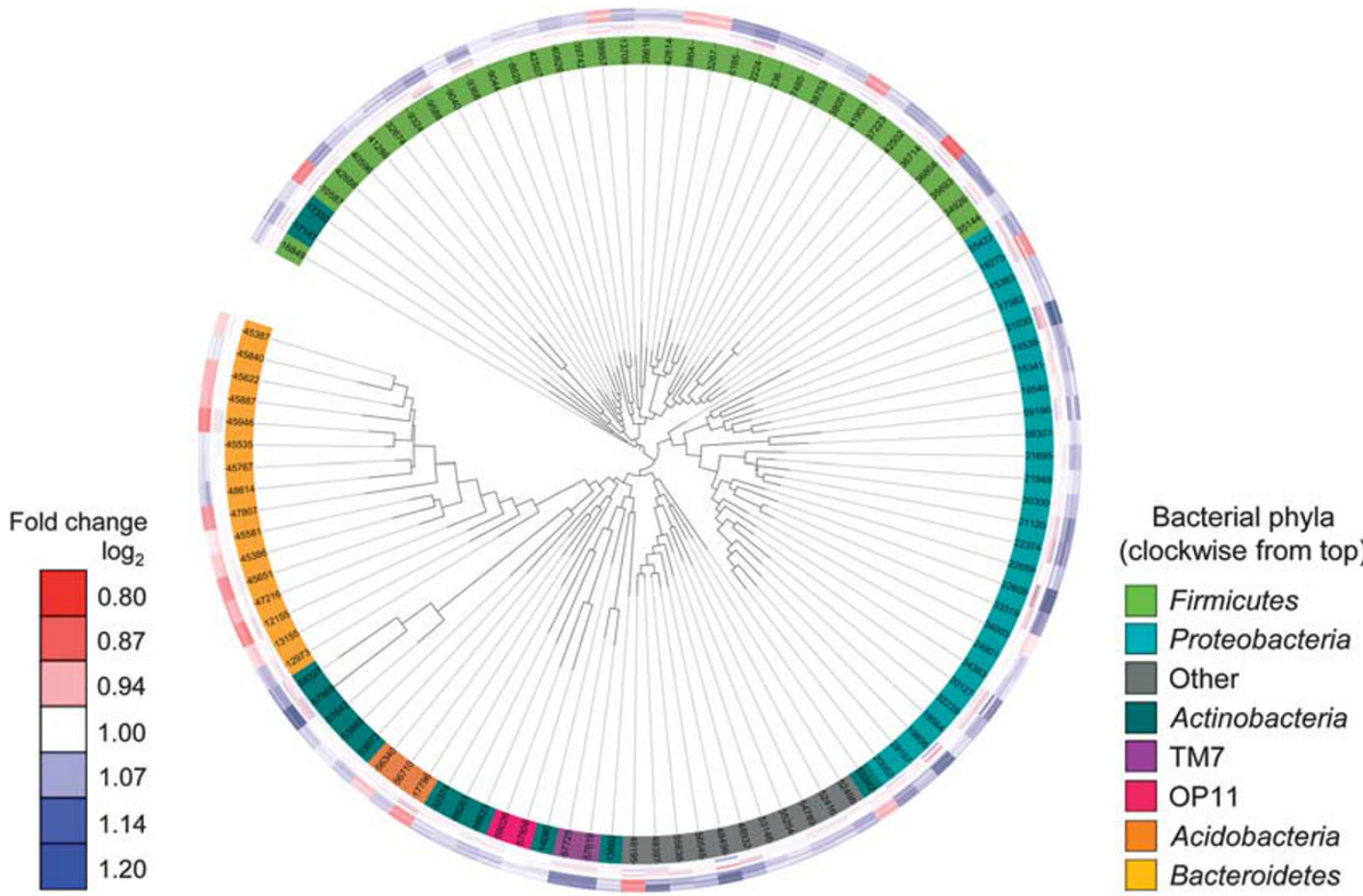

Figure 3 Differences in the composition of the fecal microbiota of MyD88 Flox and MyD88 ${ }^{\triangle \mathrm{IEC}}$ mice. The relative abundance of operational taxonomic units (OTUs) was quantified by Phylochip microarray analysis of $16 \mathrm{~S}$ rRNA gene sequences in fecal DNA from 4 MyD88Flox and 5 MyD88 ${ }^{\Delta I E C}$ littermate mice (see the Methods section for details of data analysis). A representative 16S rRNA gene from each of 109 differentially expressed OTUs was aligned and used to infer the phylogenetic tree shown in this figure. The rings around the tree comprise a heatmap where the inner ring includes the samples from MyD88Flox mice, and the outer ring includes the samples from MyD88 ${ }^{\triangle I E C}$ mice. Blue lines indicate that the OTU was more abundant in that sample than in the mean of MyD88Flox mice samples, and red lines indicate that the OTU was less abundant. The color saturation indicates the fold difference in OTU abundance for each mouse compared with the mean for MyD88 ${ }^{\mathrm{Flox}}$ mice.

$16 \mathrm{~S}$ rRNA gene sequences, in most cases with similarity $>99 \%)$ within several bacterial families (Figure 3). A large proportion of families in the phylum Bacteroidetes were decreased in abundance in MyD88 ${ }^{\triangle \mathrm{IEC}}$ mice, whereas a large proportion of families in the phylum Proteobacteria were increased. Within the phylum Firmicutes, the abundance of some families were increased while others were decreased in $\mathrm{MyD} 88^{\triangle \mathrm{IEC}}$ mice. Principal component analysis (PCA), which was used to visualize complex relationships among multiple bacterial families in individual mice, revealed significant differences between MyD88 $8^{\text {Flox }}$ and MyD88 ${ }^{\triangle \mathrm{IEC}}$ mice (Figure 4a, left panel). Interestingly, the composition of the microbiota was much more variable among individual MyD8 $8^{\text {Flox }}$ mice than among individual MyD88 ${ }^{\Delta \mathrm{IEC}}$ mice, as indicated by the tight clustering of the five MyD88 ${ }^{\triangle I E C}$ mice in the two-dimensional PCA plot. This result suggests that loss of epithelial MyD88 signaling may cause specific and reproducible changes in the bacterial community, consistent with the finding that the abundance of 2647 OTUs differed significantly between $\mathrm{MyD} 88^{\mathrm{Flox}}$ and $\mathrm{MyD} 88^{\mathrm{AIEC}}$ mice (Figure 4a, right panel). The Prediction Analysis for Microarrays method ${ }^{22}$ was used to identify "distinctive" OTUs whose relative abundance characterizes the unique microbiota of MyD88 ${ }^{\text {Flox }}$ and $\mathrm{MyD} 88^{\triangle \mathrm{IEC}}$ mice (Figure $4 \mathbf{b}$ ). This analysis identified four distinctive OTUs in the TM7 candidate division that were characteristic of MyD8 $8^{\triangle \mathrm{IEC}}$ mice, and seven OTUs within the genus
Lactobacillus (phylum Firmicutes) that were characteristic of $\mathrm{MyD} 88^{\mathrm{Flox}}$ mice. Interestingly, the relative abundance of five bacterial species that have been associated with altered innate and adaptive immunity in the gut, including Candidatus arthromitus (SFB), ${ }^{23}$ E. coli, ${ }^{24}$ Pseudomonas fluorescens, ${ }^{24}$ K. pneumoniae,${ }^{25}$ and Proteus mirabilis, ${ }^{25}$ did not differ significantly in the fecal microbiota of MyD8 $88^{\text {Flox }}$ and MyD88 ${ }^{\triangle \mathrm{IEC}}$ mice (Figure 4c). This finding suggests that translocation of $K$. pneumoniae to the MLNs of MyD88 ${ }^{\mathrm{AIEC}}$ mice (Figure 1e) was due to a specific defect in the host response to this bacterium, and not simply due to an increase in the abundance of $K$. pneumoniae in the gut microbiota.

\section{Loss of MyD88 signaling in IECs results in altered epithelial gene expression and reduced transcytosis of IgA}

To determine whether loss of epithelial MyD88 signaling resulted in altered patterns of gene expression, we isolated colonic ECs from MyD88 $8^{\text {Flox }}$ and MyD88 ${ }^{\triangle \mathrm{IEC}}$ mice and analyzed mRNA levels for 36 genes that have been implicated in innate immune responses of IECs, maintenance of epithelial barrier function, and protection against inflammation (see Supplementary Methods online for a detailed description of selection criteria for these genes). Among these genes, five (including MyD88, as a positive control) were downregulated in $\mathrm{MyD} 88^{\Delta \mathrm{IEC}}$ mice, and none were upregulated (Figure 5a). The most significantly downregulated gene was the polymeric immunoglobulin receptor 
a

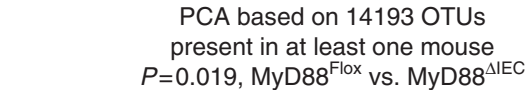

PCA based on 2647 OTUs

with significant differences across genotypes
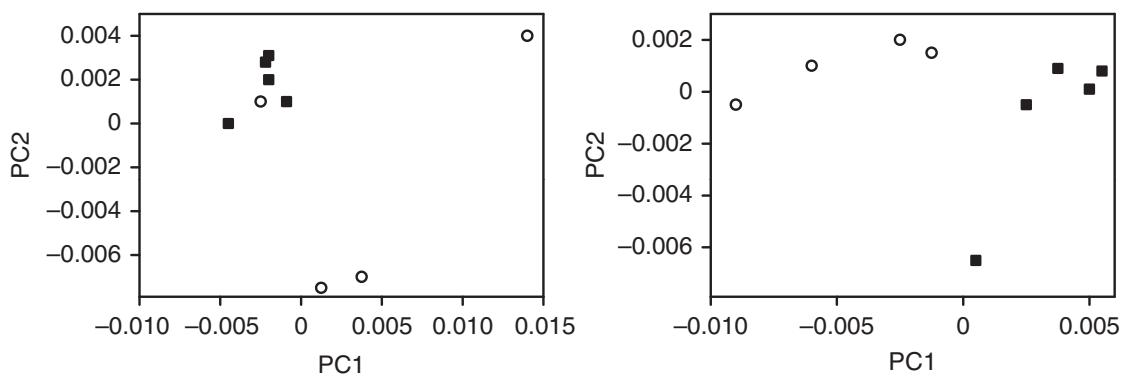

O MyD88 ${ }^{\text {Flox }}$ MyD88 $^{\Delta \mathrm{IEC}}$

b

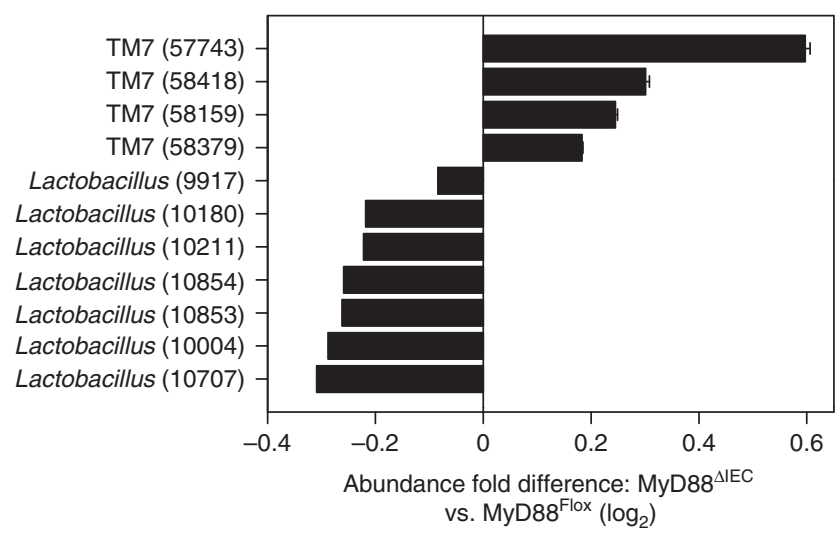

c Candidatus arthromitus (SFB)

- Escherichia coli

$\checkmark$ Proteus mirabilis

$\nabla$ Klebsiella pneumoniae

- Pseudomonas fluorescens

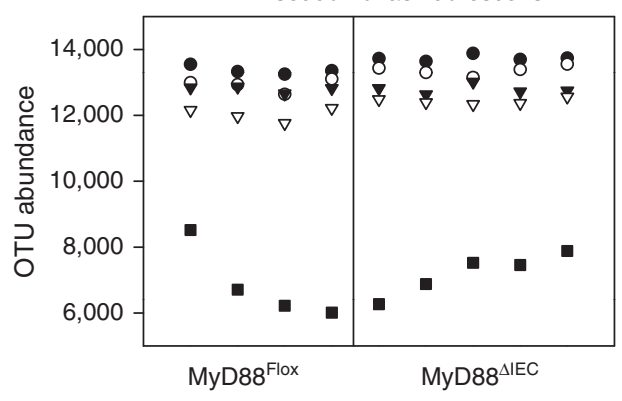

Figure 4 Loss of MyD88 expression in intestinal epithelial cells (IECs) is associated with changes in the composition of the fecal microbiota.

(a) Principal component analysis (PCA) was used to generate two-dimensional ordination plots that visualize complex relationships between the fecal microbiota of individual MyD88 Flox and MyD88 ${ }^{\mathrm{IIEC}}$ mice, based on weighted Unifrac distances between operational taxonomic units (OTUs) detected in fecal samples. The graph on the left is based on 14,193 OTUs present in at least one mouse, and the graph on the right is based on 2,647 OTUs with significant differences in abundance between MyD88 Flox and MyD88 ${ }^{\Delta I E C}$ mice. (b) Significant OTUs that characterize the distinctive microbiota of MyD88Flox and MyD88 ${ }^{\mathrm{IEC}}$ mice were identified using the Prediction Analysis for Microarrays method. Data in the bar graph are expressed as fold difference $\left(\log _{2}\right.$, mean \pm S.e.m.) in abundance between MyD88 ${ }^{\Delta \mathrm{IEC}}(n=5)$ and MyD88 ${ }^{\text {Flox }}$ mice $(n=4)$. Bars to the right of the zero line represent distinctive OTUs that were more abundant in MyD88 ${ }^{\Delta I E C}$ mice, all of which were classified in the candidate phylum TM7. Bars to the left represent distinctive OTUs that were more abundant in MyD88Flox mice, all of which were classified in the genus Lactobacillus (phylum Firmicutes). Numbers in parentheses on the $y$-axis are the IDs for individual OTUs (see Supplementary Table S1 online for complete taxonomy of the distinctive OTUs). (c) Relative abundance of five species of fecal bacteria in individual MyD88 Flox and MyD88 ${ }^{\mathrm{IEC}}$ mice. Because each of these species (except Candidatus arthromitus) comprised multiple OTUs, the OTU that represented the biggest difference in abundance between MyD88 Flox and MyD88 ${ }^{\Delta \mathrm{IEC}}$ mice is displayed.

(Pigr), the epithelial transporter for polymeric IgA antibodies. Immunostaining of colon tissues revealed that expression of $\mathrm{pIgR}$ and colocalization with IgA were severely downregulated in ECs of MyD88 ${ }^{\triangle \mathrm{IEC}}$ mice (Figure 5b), and fecal IgA levels were significantly reduced (Figure 5c). Importantly, this reduction in luminal IgA was similar to the reduction we previously reported in MyD88 ${ }^{-1-}$ mice $^{11}$, supporting a direct role for epithelial MyD88 signaling in regulating IgA transcytosis. We confirmed a direct role for epithelial MyD88 signaling in regulating pIgR expression by demonstrating that shRNA-mediated knockdown of MyD88 expression in the human HT-29 colon carcinoma cell line significantly reduced the upregulation of $\mathrm{pIgR}$ in response to bacterial stimulation (see Supplementary Figure S5b online). Other downregulated genes included mucin-2 (Muc2), the major protein constituent of intestinal mucus, and the antimicrobial peptides regenerating islet-derived III $\gamma($ RegIIIg) and defensin- $\alpha$ related sequence 1 (Defa-rs 1 ). Although there were no significant differences in goblet cell numbers in the colonic epithelia of MyD88 $8^{\text {Flox }}$ and MyD88 ${ }^{\triangle \mathrm{IEC}}$ mice (see Supplementary Figure S8 online), immunostaining revealed that the level of mucin-2 protein per goblet cell was reduced in $\mathrm{MyD} 88^{\mathrm{AIEC}}$ mice (Figure 5d). Downregulation of RegIII $\gamma$ and Defa-rs1 likely contributed to the reduced antimicrobial activity of colonic mucus in $\mathrm{MyD} 88^{\triangle \mathrm{IEC}}$ mice (Figure 2c).

\section{Loss of MyD88 signaling in colonic ECs results in increased susceptibility to dextran sulfate sodium (DSS)-induced colitis}

Inappropriate inflammatory responses to normal components of the intestinal microbiota are thought to have a major role in 
a

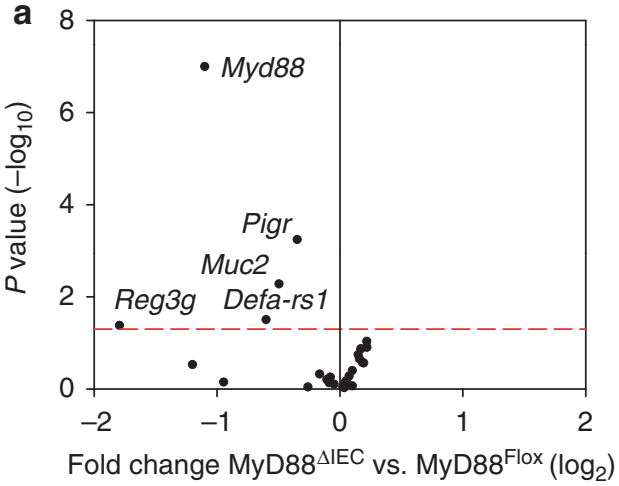

C

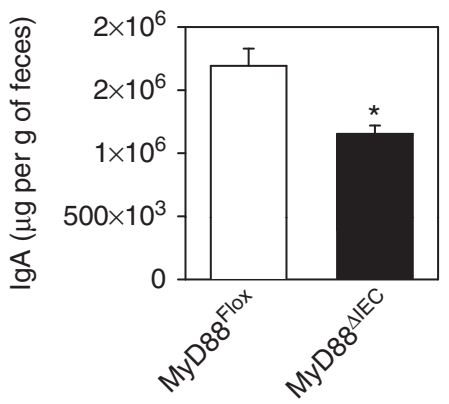

b
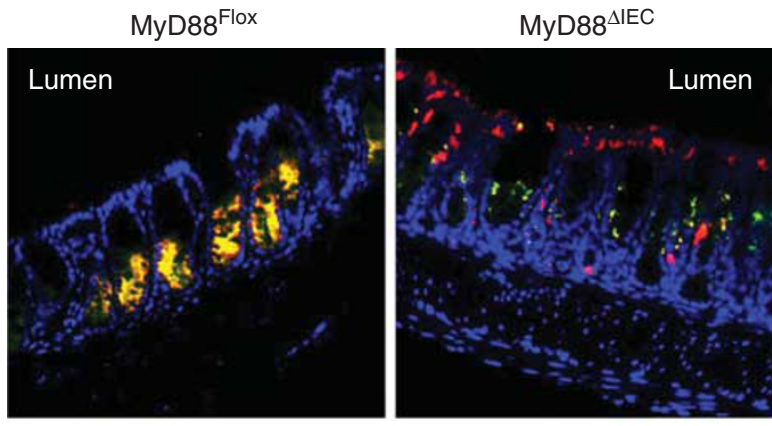

plgR

$\lg A$

DAPI

d
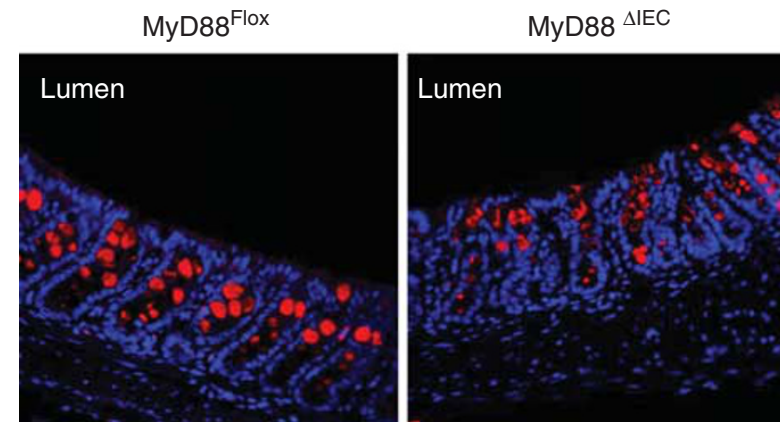

Muc2

DAPI

Figure 5 Loss of MyD88 expression alters epithelial gene expression and compromises polymeric immunoglobulin receptor (plgR)-mediated immunoglobulin (Ig)A transport. (a) Colonic epithelial cells were isolated from 8-week-old MyD88 ${ }^{\Delta \mathrm{IEC}}$ and MyD88 ${ }^{\text {Flox }}$ mice $(n=12)$. Levels of 36 individual mRNA transcripts were analyzed by Nanostring nCounter hybridization and plotted as mean fold difference $\left(\log _{2}\right)$ between MyD88 ${ }^{\Delta \mathrm{IEC}}$ and MyD88 Flox mice vs. $P$ value $\left(-\log _{10}\right)$. mRNA transcript levels for genes above the red dashed line were significantly different in MyD88 ${ }^{\Delta \mathrm{IEC}}$ mice compared with MyD88Flox mice $(P<0.05)$. Genes to the left of the zero line were downregulated, whereas genes to the right were upregulated. (b) Immunofluorescence staining of colon tissues from 9-week-old MyD88 Flox and MyD88 ${ }^{\triangle \mathrm{IEC}}$ mice (plgR=red, IgA=green, 4,6-diamidino2-phenylindole (DAPI)-stained nuclei=blue). (c) Feces were collected from 10-week-old MyD88Flox and MyD88 ${ }^{\Delta \mathrm{IEC}}$ mice and IgA levels were determined by enzyme-linked immunosorbent assay. Data are expressed as mean \pm S.e.m. $(n=5)$. The asterisk indicates that the mean for MyD88 $8^{\Delta \mathrm{EEC}}$ mice is significantly different from the mean for MyD88Flox mice $(P<0.05)$. (d) Immunofluorescence staining of colon tissues from 9-week-old $\mathrm{MyD}_{8} 8^{\mathrm{Flox}}$ and MyD88 ${ }^{\mathrm{IEC}}$ mice (Muc2=red, DAPI-stained nuclei=blue). IEC, intestinal epithelial cells.

the pathogenesis of IBD. ${ }^{4,26,27}$ Although we observed no overt inflammatory disease in MyD88 ${ }^{\triangle \mathrm{IEC}}$ mice, they exhibited several defects that have been reported in IBD patients, including reduced expression of $\mathrm{pIgR},{ }^{13} \mathrm{Muc} 2,{ }^{28}$ and antimicrobial peptides, ${ }^{17,29}$ as well as perturbed spatial relationships between microbiota and host. ${ }^{30,31}$ To test the hypothesis that MyD $88^{\Delta \mathrm{IEC}}$ mice are more susceptible to experimental colitis, acute epithelial damage was induced by administration of $2 \%$ DSS in the drinking water for 7 days. MyD88 ${ }^{\triangle \mathrm{IEC}}$ mice had significantly higher disease activity than did MyD88 ${ }^{\text {Flox }}$ mice, beginning as early as 1 day after initiation of DSS treatment (Figure 6a). At the termination of the experiment, increased inflammatory cell infiltration and epithelial destruction were observed in colons of $\mathrm{MyD} 88^{\triangle \mathrm{IEC}}$ mice (Figure $\mathbf{6 b}$ and $\mathbf{c}$ ). PCA of gene expression in colonic ECs following DSS treatment revealed significantly different patterns in MyD88 ${ }^{\triangle \mathrm{IEC}}$ and MyD88 ${ }^{\mathrm{Flox}}$ mice (Figure 6d; see Supplementary Tables S3 and S4 online for detailed gene expression data, and Supplementary Figure $\mathbf{S 9}$ online for a detailed description of PCA results). Expression of 10 genes was significantly downregulated and expression of 5 genes was upregulated in colonic ECs from MyD88 $8^{\text {Flox }}$ mice following DSS treatment (Figure 6e, top panel). Interestingly, $\mathrm{MyD} 88^{\triangle \mathrm{IEC}}$ mice were defective in their ability to upregulate the expression of the pro-inflammatory factors tumor necrosis factor (TNF), CXCL2, and interleukin (IL)-1 $\beta$ in colonic 
a

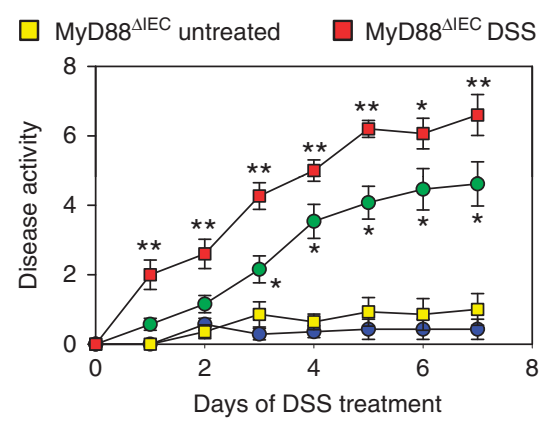

b
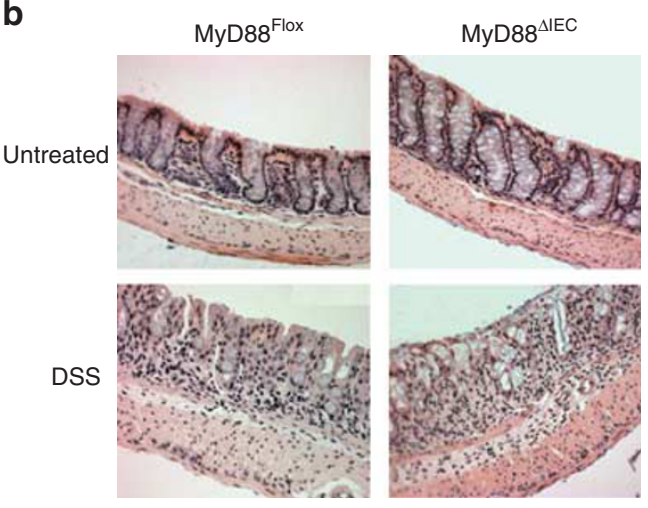

C

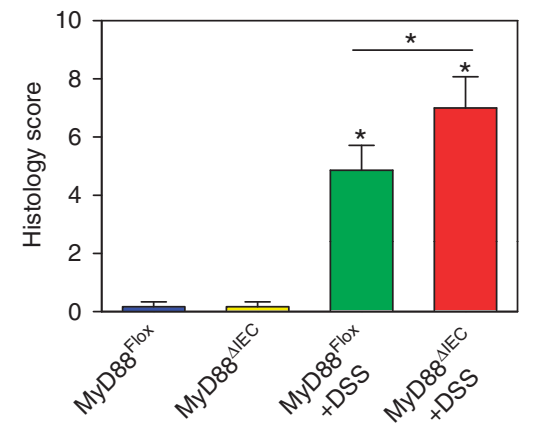

d

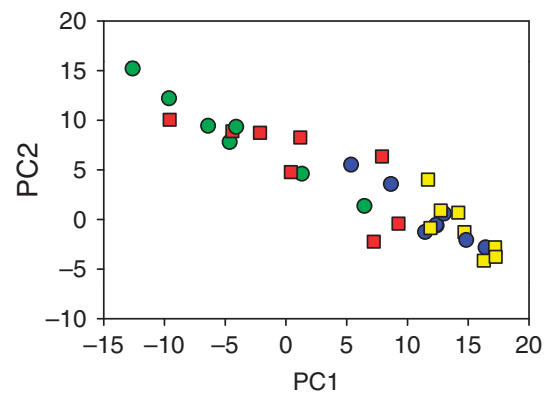

e

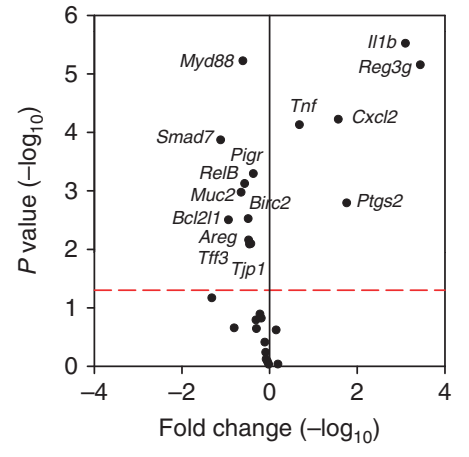

MyD88 ${ }^{\text {Flox }}+$ DSS vs. MyD88 $8^{\text {Flox }}$ - DSS

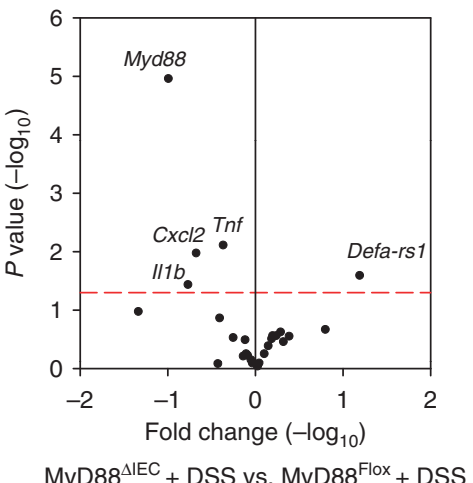

Figure 6 Loss of MyD88 expression in intestinal epithelial cells (IECs) increases the severity of dextran sulfate sodium (DSS)-induced colitis. (a) Disease activity in MyD88 Flox and MyD88 ${ }^{\mathrm{IEC}}$ mice that were given regular drinking water or $2 \% \mathrm{DSS}$ for 7 days. Data are expressed as mean \pm s.e.m. $(n=8)$. One asterisk indicates that the mean for DSS-treated mice is significantly greater than the corresponding mean for untreated mice, and two asterisks indicate that the mean for DSS-treated MyD88 ${ }^{\Delta \mathrm{ECC}}$ mice is greater than the mean for DSS-treated MyD88 ${ }^{\mathrm{Flox}}$ mice. (b) Colon histology from representative mice at day 7 . Images of formalin-fixed colon tissues stained with hematoxylin and eosin were captured with a $\times 20$ objective.

(c) Histological inflammatory scores for MyD88 ${ }^{\mathrm{Flox}}$ and MyD88 ${ }^{\mathrm{IEC}}$ mice on day 7 . Data are expressed as mean \pm S.e.m. $(n=8)$. Asterisks indicate that the means for DSS-treated mice are significantly different from the means for untreated mice of the same genotype, and that the mean for DSS-treated MyD88 ${ }^{\Delta \mathrm{IEC}}$ mice is significantly different from the mean for DSS-treated MyD88Flox mice $(P<0.05)$. (d) Principal component analysis was used to generate two-dimensional ordination plots that visualize complex relationships in expression of multiple genes in colonic EC of individual MyD88Flox and MyD88 ${ }^{\triangle \mathrm{IEC}}$ mice, with or without DSS treatment. Normalized mRNA transcript levels for 19 genes were reduced to 2 PCs (see Supplementary Figure $\mathbf{S 9}$ online for details), which are plotted for individual mice. (e) Levels of 36 individual mRNA transcripts were measured by Nanostring nCounter hybridization. Data are plotted as mean fold difference $\left(\log _{2}\right)$ between MyD88Flox mice with or without DSS treatment vs. $P$ value ( $-\log _{10}$; upper panel), and mean fold difference $\left(\log _{2}\right)$ between DSS-treated MyD88 ${ }^{\Delta \mathrm{IEC}}$ and MyD88 ${ }^{\mathrm{Flox}}$ mice vs. $P$ value $\left(-\log _{10}\right.$; lower panel). Individual dots represent the mean of treatment groups $(n=8)$. mRNA transcript levels for genes above the red dashed line were significantly different for each comparison $(P<0.05)$. Genes above the red dashed line were significantly different in DSS-treated mice compared to untreated mice $(P<0.05)$. Genes to the left of the zero line were downregulated, and genes to the right were upregulated.

ECs in response to DSS-induced damage (Figure 6e, bottom panel). Aberrant upregulation of the antimicrobial peptide Defa-rs1 in colonic ECs of MyD88 ${ }^{\triangle \mathrm{IEC}}$ mice may have been caused by increased microbial stimulation secondary to increased epithelial damage in these mice. These findings suggest that lack of epithelial MyD88 expression causes specific defects in innate immune gene expression, resulting in a compromised host response to epithelial injury and increased colonic inflammation. 


\section{DISCUSSION}

Protection against bacterial invasion and infection in the intestine is dependent on the resident microbiota, the mucus layer containing SIgA and antimicrobial peptides, and the monolayer of IECs that provide a physical and innate immune barrier. ${ }^{3}$ Here we demonstrated that loss of epithelial MyD88 signaling compromises antibacterial immunity at all three layers of defense, resulting in translocation of bacteria to MLNs. Loss of MyD88 in IECs did not cause spontaneous colitis, but rendered mice more susceptible to inflammation caused by the epithelial damaging agent DSS. These findings demonstrate the critical role of epithelial MyD88 signaling in maintenance of intestinal barrier function and protection against inflammation.

Unlike the inflammatory response generated by MyD88dependent TLR signaling in immune cells, IECs respond by producing factors involved in EC proliferation, maintenance of barrier function, innate antimicrobial immunity, and transport of SIgA. ${ }^{12,32}$ Here we report that targeted deletion of the Myd88 gene in IECs was associated with reduced expression of pIgR and epithelial transport of $\operatorname{IgA}$, providing direct evidence for the first time that epithelial MyD88 signaling regulates the production of SIgA. These SIgA antibodies in turn modulate the composition of the gut microbiota and form the first line of antigen-specific immunity that prevents invasion of IECs by members of the gut microbiota. ${ }^{33}$ This connection between epithelial MyD88 signaling, SIgA production, and host-microbial homeostasis provides a potential explanation for our previous findings that reduced pIgR expression and SIgA transport were correlated with disease severity in human IBD $^{13}$ and in mouse models of experimental colitis. ${ }^{14}$ We previously reported ${ }^{34}$ that expression of $\mathrm{pIgR}$ was upregulated by TNF and IL-1 $\beta$, the latter of which signals through a MyD88-dependent pathway. ${ }^{35}$ We found here that loss of epithelial MyD88 signaling was associated with defective production of IL-1 $\beta$ and TNF in colonic ECs in response to DSSinduced inflammation, suggesting that MyD88 may coordinate the response of IECs to autocrine and paracrine stimulation with IL-1 and TNF, as well as TLR signaling.

The intestinal epithelium is protected by a mucus layer that increases in thickness from the small to the large bowel in proportion to the density of the microbiota. ${ }^{36}$ In addition to its role as a physical barrier, the mucus serves to trap protective factors such as SIgA and antimicrobial peptides. ${ }^{3,37}$ We found that colonic ECs from MyD88 ${ }^{\triangle \mathrm{IEC}}$ mice produced significantly less Muc-2, antimicrobial peptides RegIII $\gamma$ and Defa-rs1, and SIgA, consistent with reduced antimicrobial activity in colonic mucus. Vaishnava et al. ${ }^{31}$ recently reported that mice with a targeted deletion of MyD88 in IECs had reduced expression of the antimicrobial peptide RegIII- $\gamma$ in the terminal ileum, and increased bacterial colonization of small intestinal surfaces. Gong et al. ${ }^{38}$ reported that mice transgenic for an IEC-targeted, dominantnegative mutant of MyD88 had reduced expression of antimicrobial peptides in the small intestine and increased bacterial translocation to MLNs. MyD88 signaling may also provide cues to immune cells for regulating the expression of antimicrobial and innate immune factors. Ismail et al. ${ }^{39}$ found that expression of RegIII- $\gamma$ in small intestinal $\gamma \delta$ intraepithelial lymphocytes was dependent on epithelial-specific MyD88 signaling, but not on expression of MyD88 within the intraepithelial lymphocytes themselves. Thus, epithelial MyD88 signaling provides direct and indirect signals to augment production of antimicrobial factors that segregate the microbiota from host tissues.

In our studies, a hallmark of epithelial-specific MyD88 deficiency was translocation of bacteria to the draining MLNs, including the opportunistic pathogen $K$. pneumoniae. This Gram-negative bacterium of the family Enterobacteriaceae is commonly found among the resident gut bacteria in both humans and mice, but has limited invasive potential in healthy individuals. ${ }^{40}$ Although the defect in epithelial barrier function in MyD88 ${ }^{\triangle \mathrm{IEC}}$ mice may have contributed to paracellular leakage of bacteria into the lamina propria, we did not observe translocation of commensal E. coli to the MLNs of MyD88 $\triangle$ IEC mice, even though these bacteria colonized the mucus layer of the colon. We conclude that virulence factors expressed by $K$. pneumoniae, but not by commensal E. coli, may be required for survival during transit from the mucosal surface to the MLNs. By contrast, Fukata et al. ${ }^{24}$ reported translocation of E. coli to the MLNs in mice deficient in MyD88 in all cell types. MyD88deficient mice have been shown to be highly susceptible to systemic infections with a broad range of bacteria. ${ }^{41}$ Intratracheal infection of MyD88-deficient mice with K. pneumoniae resulted in severe pneumonia, attenuated neutrophil influx, and systemic dissemination of bacteria. ${ }^{42}$ Rare cases of autosomal recessive MyD88 deficiency in humans were found to be associated with recurrent life-threatening infections with pyogenic bacteria early in life, ${ }^{41}$ including an acute urinary tract infection caused by K. pneumoniae in a 4-month-old boy. However, we did not observe systemic bacterial infections in MyD88 ${ }^{\Delta \mathrm{IEC}}$ mice. We conclude that epithelial MyD88 signaling is required for preventing the translocation of $K$. pneumoniae and possibly other opportunistic pathogens to the MLNs, but that MyD88sufficient immune cells can prevent the systemic spread of resident gut bacteria that have penetrated the mucosal barrier.

Our findings have revealed for the first time a unique role for epithelial MyD88 signaling in shaping the composition of the resident gut microbiota, including increased numbers of OTUs in the phylum Proteobacteria and decreased numbers of OTUs within the phylum Bacteroidetes in MyD88 $8^{\Delta \mathrm{IEC}}$ mice. Interestingly, similar changes in the composition of the gut microbiota have been observed in human IBD patients. ${ }^{43}$ Altered host factors that are believed to impact commensal bacteria in IBD patients include increased intestinal permeability, decreased production of antimicrobial peptides, and aberrant SIgA responses, ${ }^{43}$ all of which characterize the immune defects in mice with a targeted deletion of MyD88 in IECs. In addition to changes at the level of bacterial phyla and families, the Prediction Analysis for Microarrays technique identified four "signature" OTUs in the candidate division TM7, whose increased abundance was characteristic of the altered microbiota of MyD88 ${ }^{\Delta \mathrm{IEC}}$ mice. Importantly, increased abundance of TM7 bacteria have been reported in humans with oral inflammation ${ }^{44}$ and IBD. ${ }^{45}$ Increased abundance of TM7 bacteria has been reported in the gut microbiota of mice deficient in the NLRP6 inflammasome, 
accompanied by the development of spontaneous intestinal inflammation and increased susceptibility to DSS-induced colitis. ${ }^{46}$ Reduced production of IL-18, which transduces signals through MyD88, was characteristic of NLRP6-deficient mice. Thus, impaired MyD88 signaling in the intestine may alter the local microenvironment to favor expansion of TM7. By contrast, we did not observe changes in the gut microbiota of MyD88 $8^{\Delta \mathrm{IEC}}$ mice that have been associated with other mouse models of intestinal inflammation caused by defects in immune cells, such as increased abundance of Gram-positive segmented filamentous bacteria (C. arthromitus), which have been implicated in the expansion of Th17 cells and inflammation of the gut and extraintestinal tissues. ${ }^{23}$ Neither did we observe expansion of Proteus mirabilis nor K. pneumoniae, two Gram-negative species of the family Enterobacteriaceae, the abundance of which was increased in the gut microbiota of mice with defective immunity in dendritic cells in the intestinal lamina propria. ${ }^{25}$ Increased colonization with Enterobacteriaceae and elevated titers of Enterobacteriaceal antibodies have been associated with IBD in humans, ${ }^{47}$ and species of the genus Klebsiella are observed more frequently in the stool of ulcerative colitis patients than healthy controls. ${ }^{48}$ Our finding of unique changes in the gut microbiota of MyD88 ${ }^{\triangle \mathrm{IEC}}$ mice suggests that epithelial MyD88 signaling is required to protect against abnormal expansion of specific members of the gut microbial community.

Although loss of epithelial MyD88 signaling was not sufficient to cause spontaneous intestinal inflammation for at least 1 year of life, it was associated with increased severity of colitis following oral administration of the epithelial damaging agent, DSS. A potential mechanism for the increased susceptibility to DSS-induced colitis was suggested by our observation that MyD88 ${ }^{\Delta \mathrm{IEC}}$ mice failed to upregulate expression of TNF, CXCL2, and IL-1 $\beta$ in colonic ECs in response to epithelial damage. This finding was somewhat surprising, considering that these factors are generally considered to be pro-inflammatory and their increased expression has been linked to increased disease severity in experimental colitis. ${ }^{8}$ Our data are consistent with the notion that "physiological" inflammatory responses by IECs are a normal response to the continuous presence of the gut microbiota and are necessary for repair of damaged ECs. On the other hand, massive infiltration of gut microbes into the intestinal lamina propria following epithelial damage can result in "pathological" inflammatory responses and result in collateral damage to host tissues.

In conclusion, our findings shed new light on the beneficial effects of epithelial-microbial cross-talk mediated by MyD88 signaling, and demonstrate that MyD88-dependent TLR signaling in immune cells is insufficient to sustain protective innate immune responses in the intestine. Maintenance of intestinal homeostasis thus requires active communication among ECs, immune cells, and the gut microbiota.

\section{METHODS}

Mice. Mouse strains, on the C57BL/6 background, were purchased from Jackson Laboratories (Bar Harbor, ME). Mice of the B6.129P2$M y D 88^{t m 1 D e f r} / \mathrm{J}$ strain were intercrossed to generate mice homozygous for loxP-flanked Myd88 (MyD88 ${ }^{\text {Flox }}$ ). The B6.SJL-Tg(Vil-cre)997Gum/J strain, which is transgenic for Cre recombinase under control of the intestinal epithelial-specific mouse Vill gene, was intercrossed with MyD88 $8^{\text {Flox }}$ mice to generate mice with a targeted deletion of the Myd88 gene in ECs in the small and large bowel (MyD88 $8^{\triangle \mathrm{IEC}}$ ). Experiments were conducted with littermates generated by crossing MyD8 $8^{\Delta \mathrm{IEC}}$ mice hemizygous for the Vil1-Cre transgene with MyD88 $8^{\text {Flox }}$ mice. Acute colitis was induced by oral administration of DSS (molecular weight 36,000-50,000; MP Biomedicals, Aurora, $\mathrm{OH})$ ), and disease activity indices were calculated as described. ${ }^{49,50}$ Mice were housed in microisolator cages in an AAALACaccredited facility, and procedures were conducted in compliance with the University of Kentucky Institutional Animal Care and Use Committee.

Colonic EC isolation and analysis of mRNA levels. ECs were isolated from freshly dissected colons by dissociation with dithiothreitol and ethylenediaminetetraacetic acid and separation on a Percoll gradient, as previously described. ${ }^{51}$ Using this protocol, we typically achieve $99 \%$ purity of IECs, with contaminating $\mathrm{CD} 45^{+}$hematopoietic cells at levels of $0.4-1.3 \%{ }^{14}$ Abundance of mRNA transcripts was analyzed by Nanostring nCounter hybridization, ${ }^{52}$ and normalized using an algorithm developed by NanoString Technologies (Seattle, WA). MyD88 and pIgR mRNA in HT-29 cells were analyzed by quantitative reverse transcriptase-PCR and normalized to the level of $\beta 2$-microglobulin mRNA as described. ${ }^{15}$

Tissue histology and immunofluorescence microscopy. Dissected colons were cut lengthwise and fixed in $10 \%$ buffered formalin. Sections of formalin-fixed, paraffin-embedded colon tissues were stained with hematoxylin and eosin, or visualized by immunofluorescence using standard protocols. MyD88 was detected with a rabbit antibody (Abcam, Cambridge, MA), and pIgR was detected with a goat antibody to mouse secretory component (the extracellular domain of pIgR; R\&D Systems, Minneapolis, $\mathrm{MN}$ ), followed by horseradish peroxidase-conjugated antibody to rabbit or goat IgG (Invitrogen, Camarillo, CA) and TSA PlusTMR Reagent (Perkin-Elmer, Waltham, MA). Co-localization with IgA was detected by fluoroscein isothiocyanate-conjugated anti-mouse IgA (eBiosciences, San Diego, CA). Sections were mounted with VectaShield (Vector Laboratories, Burlingame, CA) containing 4,6-diamidino-2phenylindole to visualize nuclei and imaged on a Zeiss Axiophot confocal microscope (Carl Zeiss Microscopy LLC, Thornwood, NY) with Axiovision image software.

Bacterial culture from mouse feces and tissues. Fecal pellets were gently released from dissected colons and homogenized in phosphatebuffered saline. Luminal washes were collected by flushing colons with $5 \mathrm{ml}$ of phosphate-buffered saline, and mucus was collected by gentle scraping. Aliquots of fecal homogenates, luminal washes, and mucus were cultured for $48 \mathrm{~h}$ on $\mathrm{LB}$ agar at $37^{\circ} \mathrm{C}$ under anaerobic conditions. For analysis of bacterial translocation, MLNs were homogenized in phosphate-buffered saline and cultured anaerobically for $48 \mathrm{~h}$. E. coli strain Nissle 1917 (a generous gift of Dr Ulrich Sonnenborn, Ardeypharm $\mathrm{GmbH}$, Herdecke, Germany) was transformed to kanamycin resistance, and $\operatorname{Kan}^{\mathrm{R}}$ E. coli were delivered to the mice in the drinking water at a dose of $2.5 \times 10^{7} \mathrm{CFU} \mathrm{ml}^{-1}$ for 7 days. Feces, luminal washes, and colonic mucus were collected as described above and cultured anaerobically in $50 \mu \mathrm{g} \mathrm{ml}^{-1}$ kanamycin to enumerate CFU.

Measurement of transmucosal electrical resistance. Segments of mouse colon were mounted in $0.3 \mathrm{~cm}^{2}$ aperture Ussing chambers (Physiologic Instruments, San Diego, CA), and transmucosal electrical resistance was measured as previously described. ${ }^{53}$ Apical and basolateral recording buffers contained $118 \mathrm{mM} \mathrm{NaCl}, 5 \mathrm{mM} \mathrm{KCl}, 2 \mathrm{mM} \mathrm{NaH}_{2} \mathrm{PO}_{4}$, $1.2 \mathrm{mM} \mathrm{MgSO}_{4}, 1 \mathrm{mM} \mathrm{CaCl}_{2}, 10 \mathrm{mM}$ HEPES, $10 \mathrm{mM}$ glucose, and $22 \mathrm{mM}$ $\mathrm{NaHCO}_{3}, \mathrm{pH} 7.4$, and were bubbled with $95 \% \mathrm{O}_{2}$ and $5 \% \mathrm{CO}_{2}$ at $37^{\circ} \mathrm{C}$.

Analysis of fecal IgA and albumin by enzyme-linked immunosorbent assay. Freshly collected feces were diluted in $50 \mathrm{mM}$ Tris, $\mathrm{pH} 7.4$, 
$0.14 \mathrm{M} \mathrm{NaCl}, 1 \%$ bovine serum albumin, $0.05 \%$ Tween 20 , and analyzed by enzyme-linked immunosorbent assay as previously described ${ }^{11}$ using mouse IgA (Cat. No. E90-103) and mouse albumin (Cat. No. E90-134) ELISA Quantification Sets (Bethyl Laboratories, Montgomery, TX).

Analysis of mucus-associated antimicrobial activity. Colonic mucus was isolated as described above, diluted 1:3 in phosphate-buffered saline, and concentrated by centrifugation at 2,500 r.p.m. for $10 \mathrm{~min}$. In all, $10^{6} \mathrm{CFU}$ of $\mathrm{Kan}^{\mathrm{R}}$ E. coli from a mid-log phase culture was added to the mucus, then centrifuged together at 1,500 r.p.m. for $15 \mathrm{~min}$ at room temperature. Serial dilutions of bacterial suspensions before and after incubation with colonic mucus were cultured anaerobically for $24 \mathrm{~h}$ in $50 \mu \mathrm{g} \mathrm{ml}^{-1}$ kanamycin to enumerate CFU.

shRNA-mediated knockdown of MyD88 in human colonic ECs and bacterial invasion assays. HT-29 cells were transfected with SureSilencing plasmids encoding shRNA specific for human MyD88 or an irrelevant control shRNA (SABiosciences, Frederick, MD, cat no. KH00911P), and puromycin-resistant subclones were isolated as described. ${ }^{54}$ Binding and invasion of HT-29 cells was assessed for E. coli (strain Nissle 1917), K. pneumoniae (strain isolated from MLNs of MyD88 ${ }^{\triangle \mathrm{IEC}}$ mice) and S. typhimurium (strain SL1344) as described. Approximately $10^{6} \mathrm{CFU}$ were added to monolayers of HT-29 cells at an MOI of 10:1. After $2 \mathrm{~h}$ at $37^{\circ} \mathrm{C}$, cell monolayers were washed and lysed with $1 \%$ Triton X-100 to enumerate total cell-associated bacteria. Parallel co-cultures of bacteria and HT-29 cells were treated with gentamicin $\left(100 \mu \mathrm{g} \mathrm{ml}^{-1}\right)$ for $90 \mathrm{~min}$ to kill extracellular bacteria, washed, and cultured to enumerate intracellular bacteria. Membrane-associated bacteria were calculated by subtracting internalized CFU from total cell-associated CFU.

Analysis of the fecal microbiota. Fecal samples were collected from littermate MyD88 $8^{\text {Flox }}$ and MyD8 $8^{\triangle \mathrm{IEC}}$ mice, and frozen samples of fecal DNA (extracted with the QIAamp DNA stool kit, Qiagen, Germantown, MD) were shipped to Second Genome (San Bruno, CA) for analysis of microbial richness and diversity by the PhyloChip microarray method ${ }^{21}$ (www.secondgenome.com). Bacterial 16S rRNA genes were amplified by PCR using the forward primer $5^{\prime}$-AGRGTTTGATCMTGGCTCAG-3' and reverse primer $5^{\prime}$-GGTTACCTTGTTACGACTT-3', fragmented, biotin labeled, and hybridized to the PhyloChip Array, version G3. Stained arrays were scanned with a GeneArray scanner (Affymetrix, Inc., Santa Clara, CA), and analyzed by Affymetrix software (GeneChip Microarray Analysis Suite). All profiles are intercompared in a pair-wise fashion to determine a UniFrac distance metric, which utilizes the phylogenetic distance between OTUs to determine the dissimilarity between communities. ${ }^{56}$ For weighted UniFrac (WuniFrac), both the abundance and dissimilarities among OTUs were considered. The phylogenetic tree shown in Figure 3 was generated using the "Interactive Tree of Life" software tool. ${ }^{57}$ Based on 14,193 OTUs present in at least one of the mice, a Welch $t$-test was performed across the two genotypes using abundance metrics. PCA was used to position points on two-dimensional ordination plots based on dissimilarity values (Figure 4a). Significant OTUs whose abundance characterizes each mouse genotype (Figure $\mathbf{4 b}$ ) were identified by Prediction Analysis for Microarrays, which utilizes a nearest shrunken centroid method. ${ }^{22}$

Statistical analyses. Statistical differences in mRNA abundance, CFU, and disease activity were determined by analysis of variance and Fisher's protected least significant difference test. PCA was used for multifactorial clustering of gene expression data (see Supplementary Methods and Supplementary Figure S5 online for details). A one-tailed Student's $t$-test was used to compare transmucosal electrical resistance values for colon tissues. Permutational multivariate analysis of variance was utilized to compare the fecal microbiota between mouse genotypes, based on distance matrices of OTUs.
SUPPLEMENTARY MATERIAL is linked to the online version of the paper at http://www.nature.com/mi

\section{ACKNOWLEDGMENTS}

We thank Dr Jiayou Zhang, University of Kentucky, for supplying a bacterial plasmid encoding kanamycin resistance and green fluorescence protein, and Dr Jerrold Turner, University of Chicago, for helpful discussions. This study was supported by National Institutes of Health grant R21Al069027 (CSK) and a Crohn's \& Colitis Foundation of America Senior Research Award (CSK).

\section{DISCLOSURE}

The authors declared no conflict of interest.

(C) 2012 Society for Mucosal Immunology

\section{REFERENCES}

1. Hooper, L.V. \& Macpherson, A.J. Immune adaptations that maintain homeostasis with the intestinal microbiota. Nat. Rev. Immunol. 10, 159-169 (2010).

2. Carvalho, F.A., Aitken, J.D., Vijay-Kumar, M. \& Gewirtz, A.T. Toll-like receptor-gut microbiota interactions: perturb at your own risk!. Annu. Rev. Physiol. 74, 177-198 (2011).

3. Gill, N., Wlodarska, M. \& Finlay, B.B. Roadblocks in the gut: barriers to enteric infection. Cell. Microbiol. 13, 660-669 (2011).

4. Kaser, A., Zeissig, S. \& Blumberg, R.S. Genes and environment: how will our concepts on the pathophysiology of IBD develop in the future? Dig. Dis. 28, 395-405 (2010).

5. Cario, E. Heads up! How the intestinal epithelium safeguards mucosal barrier immunity through the inflammasome and beyond. Curr. Opin. Gastroenterol. 26, 583-590 (2010)

6. Cario, E. Toll-like receptors in inflammatory bowel diseases: a decade later. Inflamm. Bowel. Dis. 16, 1583-1597 (2010).

7. Jobin, C. MyD88 signaling in the intestine: Dr Jekyll and Mr Hyde? Gastroenterology 139, 383-385 (2010).

8. Rakoff-Nahoum, S., Paglino, J., Eslami-Varzaneh, F., Edberg, S. \& Medzhitov, R. Recognition of commensal microflora by Toll-like receptors is required for intestinal homeostasis. Cell 118, 229-241 (2004).

9. Brandl, K. et al. MyD88 signaling in nonhematopoietic cells protects mice against induced colitis by regulating specific EGF receptor ligands. Proc. Natl. Acad. Sci. USA 107, 19967-19972 (2010)

10. Asquith, M.J., Boulard, O., Powrie, F. \& Maloy, K.J. Pathogenic and protective roles of MyD88 in leukocytes and epithelial cells in mouse models of inflammatory bowel disease. Gastroenterology 139, 519-529e511-512 (2010)

11. Macpherson, A.J., Geuking, M.B. \& McCoy, K.D. Immunoglobulin A: a bridge between innate and adaptive immunity. Curr. Opin. Gastroenterol. 27, 529-533 (2011).

12. Johansen, F.-E. \& Kaetzel, C.S. Regulation of the polymeric immunoglobulin receptor and IgA transport: new advances in environmental factors that stimulate plgR expression and its role in mucosal immunity. Mucosal Immunol. 4, 598-602 (2011).

13. Arsenescu, R. et al. Signature biomarkers in Crohn's disease: toward a molecular classification. Mucosal Immunol. 1, 399-411 (2008).

14. Frantz, A.L. Multifactorial patterns of gene expression in colonic epithelial cells predict disease phenotypes in experimental colitis. Inflamm. Bowel Dis. (2012) in press.

15. Bruno, M.E. et al. Regulation of the polymeric immunoglobulin receptor in intestinal epithelial cells by Enterobacteriaceae: implications for mucosal homeostasis. Immunol. Invest. 39, 356-382 (2010).

16. Linden, S.K., Sutton, P., Karlsson, N.G., Korolik, V. \& McGuckin, M.A. Mucins in the mucosal barrier to infection. Mucosal Immunol. 1, 183-197 (2008).

17. Wehkamp, J. \& Stange, E.F. Is there a role for defensins in IBD? Inflamm Bowel Dis. 14 (Suppl 2), S85-87 (2008).

18. Mantis, N.J. \& Forbes, S.J. Secretory IgA: arresting microbial pathogens at epithelial borders. Immunol. Invest. 39, 383-406 (2010).

19. Pinto, D., Robine, S., Jaisser, F., El Marjou, F.E. \& Louvard, D. Regulatory sequences of the mouse villin gene that efficiently drive transgenic expression in immature and differentiated epithelial cells of small and large intestines. J. Biol. Chem. 274, 6476-6482 (1999). 
20. Schultz, M. Clinical use of E. coli Nissle 1917 in inflammatory bowel disease. Inflamm. Bowel Dis. 14, 1012-1018 (2008)

21. Loy, A., Pester, M. \& Steger, D. Phylogenetic microarrays for cultivationindependent identification and metabolic characterization of microorganisms in complex samples. Methods Mol. Biol. 688, 187-206 (2010).

22. Guo, Y., Hastie, T. \& Tibshirani, R. Regularized linear discriminant analysis and its application in microarrays. Biostatistics 8, 86-100 (2007).

23. Ivanov, I.I. et al. Induction of intestinal Th17 cells by segmented filamentous bacteria. Cell 139, 485-498 (2009).

24. Fukata, M. et al. Toll-like receptor-4 is required for intestinal response to epithelial injury and limiting bacterial translocation in a murine mode of acute colitis. Am. J. Physiol. Gastrointest. Liver Physiol. 288, G1055-1065 (2005).

25. Garrett, W.S. et al. Enterobacteriaceae act in concert with the gut microbiota to induce spontaneous and maternally transmitted colitis. Cell Host Microbe 8, 292-300 (2010).

26. Khor, B., Gardet, A. \& Xavier, R.J. Genetics and pathogenesis of inflammatory bowel disease. Nature 474, 307-317 (2011)

27. Maloy, K.J. \& Powrie, F. Intestinal homeostasis and its breakdown in inflammatory bowel disease. Nature 474, 298-306 (2011).

28. Moehle, C. et al. Aberrant intestinal expression and allelic variants of mucin genes associated with inflammatory bowel disease. J. Mol. Med. (Berlin) 84, 1055-1066 (2006)

29. Cash, H.L., Whitham, C.V., Behrendt, C.L. \& Hooper, L.V. Symbiotic bacteria direct expression of an intestinal bactericidal lectin. Science 313, 1126-1130 (2006)

30. Turner, J.R. Intestinal mucosal barrier function in health and disease. Nat. Rev. Immunol. 9, 799-809 (2009)

31. Vaishnava, S. et al. The antibacterial lectin Reglll $\gamma$ promotes the spatial segregation of microbiota and host in the intestine. Science 334, 255-258 (2011).

32. Abreu, M.T. Toll-like receptor signalling in the intestinal epithelium: how bacterial recognition shapes intestinal function. Nat. Rev. Immunol. 10, 131-144 (2010).

33. Macpherson, A.J., McCoy, K.D., Johansen, F.-E. \& Brandtzaeg, P. The immune geography of IgA induction and function. Mucosal Immunol. 1, 11-22 (2008).

34. Blanch, V.J., Piskurich, J.F. \& Kaetzel, C.S. Cutting edge: coordinate regulation of IFN regulatory factor-1 and the polymeric Ig receptor by proinflammatory cytokines. J. Immunol. 162, 1232-1235 (1999).

35. Casanova, J.L., Abel, L. \& Quintana-Murci, L. Human TLRs and IL-1Rs in host defense: natural insights from evolutionary, epidemiological, and clinical genetics. Annu. Rev. Immunol. 29, 447-491 (2011).

36. Johansson, M.E. \& Hansson, G.C. Microbiology. Keeping bacteria at a distance. Science 334, 182-183 (2011)

37. Mantis, N.J., Rol, N. \& Corthesy, B. Secretory lgA's complex roles in immunity and mucosal homeostasis in the gut. Mucosal Immunol. 4, 603-611 (2011).

38. Gong, J. et al. Epithelial-specific blockade of MyD88-dependent pathway causes spontaneous small intestinal inflammation. Clin. Immunol. 136, 245-256 (2010)

39. Ismail, A.S. et al. $\gamma \delta$ intraepithelial lymphocytes are essential mediators of host-microbial homeostasis at the intestinal mucosal surface. Proc. Natl. Acad. Sci. USA 108, 8743-8748 (2011).

40. Lau, H.Y., Huffnagle, G.B. \& Moore, T.A. Host and microbiota factors that control Klebsiella pneumoniae mucosal colonization in mice. Microbes Infect. 10, 1283-1290 (2008).
41. von Bernuth, $\mathrm{H}$. et al. Pyogenic bacterial infections in humans with MyD88 deficiency. Science 321, 691-696 (2008).

42. Cai, S., Batra, S., Shen, L., Wakamatsu, N. \& Jeyaseelan, S. Both TRIF- and MyD88-dependent signaling contribute to host defense against pulmonary Klebsiella infection. J. Immunol. 183, 6629-6638 (2009).

43. Chassaing, B. \& Darfeuille-Michaud, A. The commensal microbiota and enteropathogens in the pathogenesis of inflammatory bowel diseases. Gastroenterology 140, 1720-1728 (2011).

44. Colombo, A.P. et al. Comparisons of subgingival microbial profiles of refractory periodontitis, severe periodontitis, and periodontal health using the human oral microbe identification microarray. J. Periodontol. 80, 1421-1432 (2009)

45. Kuehbacher, T. et al. Intestinal TM7 bacterial phylogenies in active inflammatory bowel disease. J. Med. Microbiol. 57, 1569-1576 (2008).

46. Elinav, E. et al. NLRP6 inflammasome regulates colonic microbial ecology and risk for colitis. Cell 145, 745-757 (2011)

47. Packey, C.D. \& Sartor, R.B. Commensal bacteria, traditional and opportunistic pathogens, dysbiosis and bacterial killing in inflammatory bowel diseases. Curr. Opin. Infect. Dis. 22, 292-301 (2009).

48. Dorofeyev, A.E., Vasilenko, I.V. \& Rassokhina, O.A. Joint extraintestinal manifestations in ulcerative colitis. Dig. Dis. 27, 502-510 (2009)

49. Qualls, J.E., Tuna, H., Kaplan, A.M. \& Cohen, D.A. Suppression of experimental colitis in mice by CD11c+ dendritic cells. Inflamm. Bowel Dis. 15, 236-247 (2009).

50. Murthy, A.K., Dubose, C.N., Banas, J.A., Coalson, J.J. \& Arulanandam, B.P. Contribution of polymeric immunoglobulin receptor to regulation of intestinal inflammation in dextran sulfate sodium-induced colitis. J. Gastroenterol. Hepatol. 21, 1372-1380 (2006).

51. Weigmann, B. et al. Isolation and subsequent analysis of murine lamina propria mononuclear cells from colonic tissue. Nat. Protoc. 2, 2307-2311 (2007).

52. Geiss, G.K. et al. Direct multiplexed measurement of gene expression with color-coded probe pairs. Nat. Biotechnol. 26, 317-325 (2008).

53. Weber, C.R. et al. Epithelial myosin light chain kinase activation induces mucosal interleukin-13 expression to alter tight junction ion selectivity. J. Biol. Chem. 285, 12037-12046 (2010).

54. Bruno, M.E., Frantz, A.L., Rogier, E.W., Johansen, F.E. \& Kaetzel, C.S. Regulation of the polymeric immunoglobulin receptor by the classical and alternative NF- $\kappa \mathrm{B}$ pathways in intestinal epithelial cells. Mucosal Immunol. 4, 468-478 (2011)

55. Criss, A.K., Ahlgren, D.M., Jou, T.S., McCormick, B.A. \& Casanova, J.E The GTPase Rac1 selectively regulates Salmonella invasion at the apical plasma membrane of polarized epithelial cells. J. Cell. Sci. 114, 1331-1341 (2001)

56. Lozupone, C., Lladser, M.E., Knights, D., Stombaugh, J. \& Knight, R. UniFrac: an effective distance metric for microbial community comparison. ISME J. 5, 169-172 (2010).

57. Letunic, I. \& Bork, P. Interactive Tree Of Life (iTOL): an online tool for phylogenetic tree display and annotation. Bioinformatics 23, 127-128 (2007).

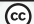

This work is licensed under the Creative Commons Attribution-NonCommercial-No Derivative Works 3.0 Unported License. To view a copy of this license, visit http://creativecommons.org/licenses/by-nc-nd/3.0/ 